\title{
Predicting Success: Patterns of Cortical Activation and Deactivation Prior to Response Inhibition
}

\author{
Robert L. Hester ${ }^{1}$, Kevin Murphy ${ }^{1}$, John J. Foxe ${ }^{2}$, Deirdre M. Foxe ${ }^{2}$, \\ Daniel C. Javitt ${ }^{2}$, and Hugh Garavan ${ }^{1}$
}

\begin{abstract}
The present study investigated the relationships between attention and other preparatory processes prior to a response inhibition task and the processes involved in the inhibition itself. To achieve this, a mixed fMRI design was employed to identify the functional areas activated during both inhibition decision events and the block of trials following a visual cue introduced 2 to $7 \mathrm{sec}$ prior (cue period). Preparing for successful performance produced increases in activation for both the cue period and the inhibition itself in the frontoparietal
\end{abstract}

\section{INTRODUCTION}

Possessing information that a challenging cognitive task will soon be presented has been shown to improve a participant's task performance (Rogers \& Monsell, 1995). Recent neuroimaging studies have attempted to isolate the neuroanatomical regions activated during this task preparation phase and have implicated both frontal and midline brain regions (Sakai \& Passingham, 2003; Brass \& von Cramon, 2002; Luks, Simpson, Feiwell, \& Miller, 2002; MacDonald, Cohen, Stenger, \& Carter, 2000). The anterior prefrontal cortex (Sakai \& Passingham, 2003) (PFC), dorsolateral PFC (MacDonald et al., 2000), inferior frontal junction, and pre-SMA (Brass \& von Cramon, 2002) have been shown to activate during the preparation for a cognitively demanding task, with the suggestion that these regions are involved in the implementation and maintenance of task-appropriate goals and behaviors. The anterior cingulate cortex (ACC) has also been found to be active in task preparation paradigms, particularly in response to cues that produce conflict by potentiating competing task behaviors (Luks et al., 2002; MacDonald et al., 2000). The detection of conflict during task preparation is consistent with the hypothesized role of the ACC in other types of information processing (Garavan, Ross, Murphy, Roche, \& Stein, 2002; van Veen, Cohen, Botvinick, Stenger, \& Carter, 2001; van Veen \& Carter, 2002).

A greater understanding of how people exert top-down control over cognitive processing at a neurophysio-

${ }^{1}$ Trinity College, ${ }^{2}$ Nathan S. Kline Institute for Psychiatric Research cortical network. Furthermore, preparation produced activation decreases in midline areas (insula and medial prefrontal) argued to be responsible for monitoring internal emotional states, and these cue period deactivations alone predicted subsequent success or failure. The results suggest that when cues are provided to signify the imminent requirement for behavioral control, successful performance results from a coordinated pattern of preparatory activation in task-relevant areas and deactivation of task-irrelevant ones.

logical level is important not only to our understanding of how people voluntarily control their actions in response to dynamic and rapidly changing environments, but may also prove illuminating to clinical disorders where these skills are impaired, such as attention deficit hyperactivity disorder (Stevens, Quittner, Zuckerman, \& Moore, 2002; Rapport, Van Voorhis, Tzelepis, \& Friedman, 2001; Barkley, 1997), traumatic brain injury (TBI) and other "disinhibition" syndromes (Tekin \& Cummings, 2002; Cummings \& McPherson, 2001; Konrad, Gauggel, Manz, \& Scholl, 2000). Given this application, we attempted to extend previous functional neuroimaging studies by comparing the neural activation maps prior to successful and failed task performance during a response inhibition task. The task employed a mixed block and event-related fMRI design to identify the functional areas activated during both no-go decision events, and the block of trials following a visual cue that was introduced 2 to $7 \mathrm{sec}$ prior to the no-go event (cue period). Eighty no-go events (lures) were pseudorandomly placed throughout the sequence of 1176 trials, with $50 \%$ of the lures preceded by a cue.

The aim of the present study was to identify patterns of preparatory activation in order to observe how heightened attention is achieved. We were particularly interested in examining whether performance and activation patterns on the subsequent no-go event were related to the pattern of activation during the cue period. Finally, by contrasting cue periods that preceded success with those that preceded failures to inhibit, we wished to determine the neuroanatomical precursors for successful behavioral control. 


\section{RESULTS}

\section{Behavioral Results}

The behavioral results demonstrated significantly fewer ERRORS for cued events than uncued, $20 \%$ vs. $40 \%$; $t(14)=5.85, p<.001$. A comparison of the mean RT for the cue period and a comparable period prior to uncued lures revealed a significant increase in RT for cue period trials, 370 vs. 340 msec; $t$ (14) 4.155, $p<.001$. Mean RT during the cue period prior to STOPS was significantly slower than that for ERRORS, 382 vs. $310 \mathrm{msec} ; t(14) 4.85$, $p<.001$. The length of the cue period (2-4 vs. 5-7 sec)

Table 1. Event-Related Activation for Cued and Uncued Successful Response Inhibition (STOPS)

\begin{tabular}{|c|c|c|c|c|c|c|c|}
\hline \multirow[b]{2}{*}{ Structure } & \multirow[b]{2}{*}{ Brodmann's area } & \multirow[b]{2}{*}{ Hemisphere } & \multirow[b]{2}{*}{ Volume $(\mu l)$} & \multicolumn{3}{|c|}{ Center of Mass } & \multirow[b]{2}{*}{ Sig } \\
\hline & & & & $x$ & $y$ & $z$ & \\
\hline \multicolumn{8}{|l|}{ Frontal lobe } \\
\hline \multirow[t]{4}{*}{ Middle frontal gyrus } & $46 / 9$ & $\mathrm{R}$ & 9834 & 38 & -31 & 23 & $* *$ \\
\hline & $10 / 46$ & $\mathrm{~L}$ & 2112 & -40 & -38 & 18 & $* *$ \\
\hline & $9 / 6$ & $\mathrm{~L}$ & 752 & -49 & -5 & 38 & $* *$ \\
\hline & 6 & $\mathrm{~L}$ & 412 & -30 & 4 & 51 & $* *$ \\
\hline Inferior frontal gyrus & 47 & $\mathrm{~L}$ & 353 & -48 & -40 & -7 & \\
\hline Middle frontal/cingulate gyrus & 6 & $\mathrm{~B}$ & 230 & 0 & 0 & 60 & \\
\hline Middle frontal gyrus & 6 & $\mathrm{~L}$ & 206 & -37 & -9 & 44 & $*$ \\
\hline \multicolumn{8}{|l|}{ Parietal lobe } \\
\hline \multirow[t]{2}{*}{ Inferior parietal lobule } & 40 & $\mathrm{R}$ & 10135 & 35 & 52 & 40 & $* *$ \\
\hline & 40 & $\mathrm{~L}$ & 5869 & -39 & 51 & 41 & $* *$ \\
\hline Precuneus & 7 & $\mathrm{~L}$ & 204 & -9 & 73 & 45 & $* *$ \\
\hline \multicolumn{8}{|l|}{ Temporal lobe } \\
\hline \multirow[t]{2}{*}{ Middle temporal gyrus } & $22 / 21$ & $\mathrm{R}$ & 1268 & 56 & 33 & 3 & $* *$ \\
\hline & 37 & $\mathrm{~L}$ & 162 & -55 & 54 & -8 & $* *$ \\
\hline Parahippocampal gyrus & & $\mathrm{R}$ & 219 & 17 & 21 & -27 & $* *$ \\
\hline Middle temporal & 22 & $\mathrm{~L}$ & 161 & -53 & 45 & 20 & \\
\hline \multicolumn{8}{|l|}{ Subcortical/insula } \\
\hline \multirow[t]{2}{*}{ Thalamus } & & $\mathrm{B}$ & 947 & 14 & 4 & 10 & $*$ \\
\hline & & $\mathrm{B}$ & 377 & 17 & 14 & 17 & $*$ \\
\hline \multirow[t]{2}{*}{ Insula } & 13 & $\mathrm{R}$ & 390 & 55 & 31 & 21 & $* *$ \\
\hline & 13 & $\mathrm{R}$ & 216 & 44 & 35 & 20 & \\
\hline Lentiform/globus pallidus & & $\mathrm{L}$ & 872 & -15 & 3 & 9 & $* *$ \\
\hline Caudate & & $\mathrm{R}$ & 173 & 13 & -10 & 12 & \\
\hline \multicolumn{8}{|l|}{ Occipital lobe } \\
\hline Superior occipital gyrus & 19 & $\mathrm{R}$ & 339 & 35 & 74 & 29 & $* *$ \\
\hline
\end{tabular}

Positive values for $x, y$, and $z$ coordinates denote locations that are right, posterior, and superior relative to the anterior commissure, respectively. Significance test results (Sig.) indicate areas of greater activation in the cued STOPS condition when compared to uncued STOPS using pairwise $t$ tests. All differences were in the direction of greater activation in the cued condition.

$* p<.05$.

$* * p<.01$. 
did not appear to influence performance for the no-go events, with $56 \%$ of cued errors made on the shorter cue period trials, $56 \%$ vs. $44 \%$; $t(14)-1.24, p=.233$.

\section{Event-Related Activation}

Bilateral activation of frontal, parietal, temporal, and subcortical regions consistent with previous studies using the go/no-go task (Watanabe et al., 2002; Liddle, Kiehl, \& Smith, 2001; Garavan, Ross, \& Stein, 1999; Garavan et al., 2002; Konishi, Nakajima, Uchida, Sekihara, \& Miyashita, 1998) was observed for both the cued and uncued STOPS (Table 1 and Figure 1A). The activation maps indicate that while there was significant regional overlap, the regions of interest (ROI) analysis, corrected using a modified Bonferroni procedure for multiple comparisons (Keppel, 1991), indicated that cued STOPS showed significantly greater activation than uncued STOPS in a number of regions including the middle frontal and parietal regions. Bilateral inferior frontal and parietal activation was also evident for ERRORS, as well as cingulate, transverse temporal, thalamic, and insula activation. A similar pattern of greater activation in the cued condition was observed in the ERROR activation maps (Table 2 and Figure 1B).

\section{Cue Period Activation}

Examination of the cue period activation map prior to STOPS revealed a network of regions including the middle frontal, superior parietal regions, pre-SMA/dorsal ACC region, temporal, occipital, insula, and fusiform gyri (see Table 3 and Figure 1C). The activation map for the cue period prior to ERRORS indicated only one cluster of activation above threshold in the posterior cingulate region. An ROI analysis compared the level of activation for the cue period prior to STOPS with those prior to ERRORS. The results indicated two regions, the left medial frontal gyrus (Brodmann's area 32/9) and left insula (BA 13), which were significantly deactivated prior
Figure 1. (A) Event-related activation map for the cued and uncued STOPS;

(B) event-related activation map for cued and uncued ERRORS; (C) map of block-related cue period activation prior to STOPS and ERRORS.

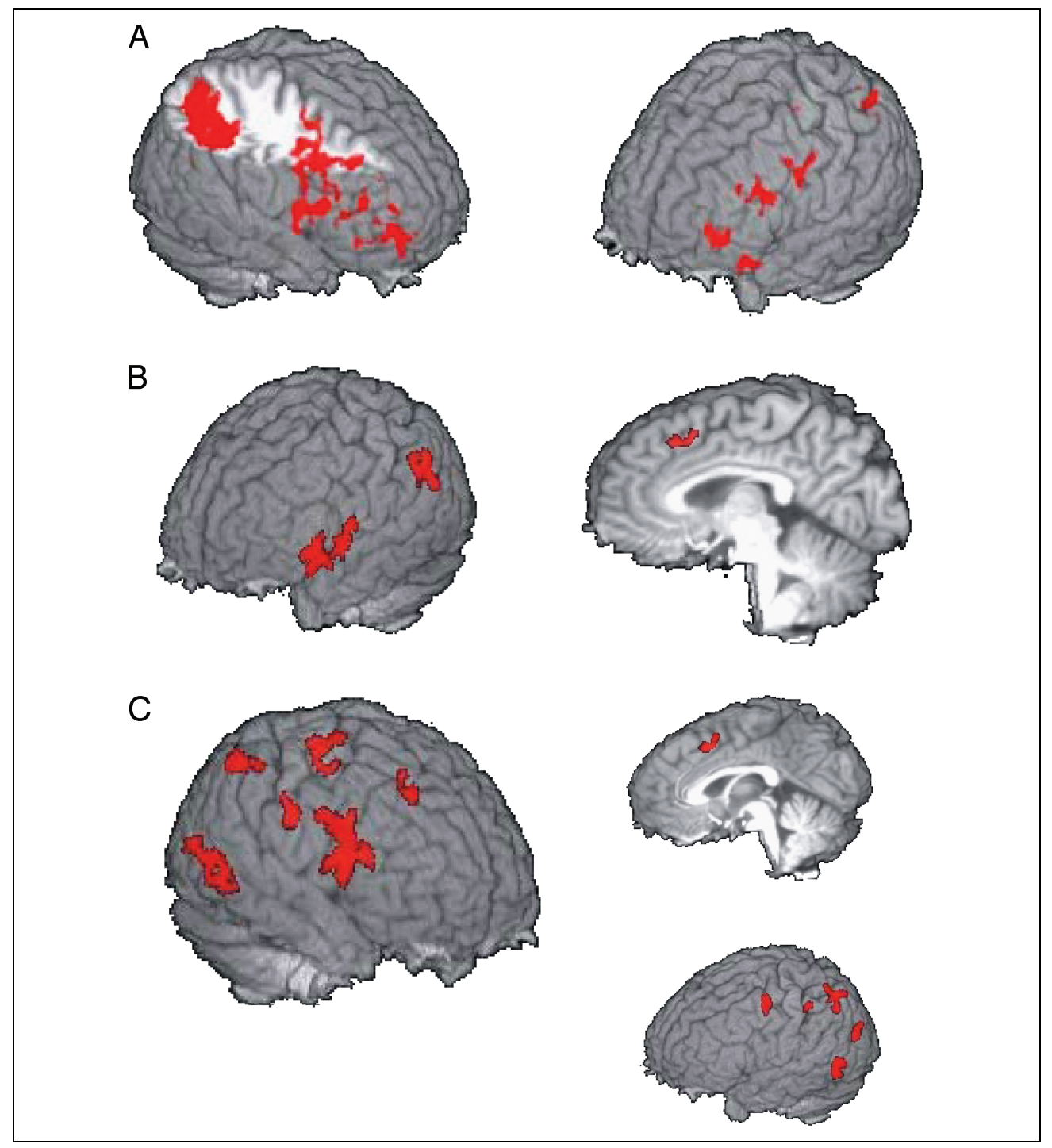


Table 2. Event-Related Activation for Cued and Uncued Commission Errors (ERRORS)

\begin{tabular}{|c|c|c|c|c|c|c|c|}
\hline \multirow[b]{2}{*}{ Structure } & \multirow[b]{2}{*}{ Brodmann's area } & \multirow[b]{2}{*}{ Hemisphere } & \multirow[b]{2}{*}{ Volume $(\mu l)$} & \multicolumn{3}{|c|}{ Center of Mass } & \multirow[b]{2}{*}{ Sig } \\
\hline & & & & $x$ & $y$ & $z$ & \\
\hline \multicolumn{8}{|l|}{ Frontal lobe } \\
\hline \multirow[t]{3}{*}{ Inferior frontal gyrus } & 47 & $\mathrm{~L}$ & 1252 & -45 & -23 & -3 & $* *$ \\
\hline & 10 & $\mathrm{R}$ & 168 & 44 & -39 & 1 & $* *$ \\
\hline & 44 & $\mathrm{~L}$ & 155 & -56 & -14 & 10 & $* *$ \\
\hline \multirow[t]{2}{*}{ Cingulate gyrus } & 32 & $\mathrm{~L}$ & 268 & -5 & -25 & 38 & $*$ \\
\hline & 32 & $\mathrm{~L}$ & 264 & -2 & -8 & 51 & \\
\hline \multicolumn{8}{|l|}{ Parietal lobe } \\
\hline Inferior parietal lobule & 40 & $\mathrm{R}$ & 1170 & 50 & 41 & 40 & $* *$ \\
\hline Supramarginal gyrus & 40 & $\mathrm{~L}$ & 768 & -56 & 45 & 31 & $* *$ \\
\hline Superior parietal lobule & 7 & $\mathrm{R}$ & 248 & 8 & 66 & 47 & $*$ \\
\hline Cingulate gyrus & & $\mathrm{B}$ & 189 & 0 & 21 & 24 & \\
\hline \multicolumn{8}{|l|}{ Temporal lobe } \\
\hline Transverse temporal & 42 & $\mathrm{~L}$ & 146 & -62 & 14 & 12 & $* *$ \\
\hline \multicolumn{8}{|l|}{ Subcortical/insula } \\
\hline Insula & 13 & $\mathrm{~L}$ & 687 & -45 & -3 & 2 & $* *$ \\
\hline Thalamus & & $\mathrm{R}$ & 216 & 13 & 26 & 8 & $* *$ \\
\hline Corpus callosum & & & 189 & 0 & 21 & 24 & \\
\hline
\end{tabular}

Positive values for $x, y$, and $z$ coordinates denote locations that are right, posterior, and superior relative to the anterior commissure, respectively. Significance test (Sig.) results indicate areas of greater activation in the cued ERRORS condition when compared to uncued ERRORS using pairwise $t$ tests.

$* p<.05$.

$* * p<.01$.

to STOPS relative to errors, whereas the right posterior cingulate (BA 31/30) significantly decreased in activity (but remained above baseline) (Figure 2). None of the positively activated areas differed between STOPS and ERRORS.

Given these results, we performed an ROI comparison between the cue period prior to STOPS and a comparable period prior to uncued STOPS. The regions of interest were those seen in the cue period. The analysis indicated that all areas were significantly different $(p<$ .01 ), with the level of activation being greater during the cue period in all but five regions where significant deactivation occurred in the left medial frontal gyrus (BA 32/9), caudate, left precuneus/cingulate, and left insula (see Table 3). The left medial frontal and left insula regions had also been the areas significantly deactivated during the cue period prior to STOPS.

The effect of cueing on those areas involved in response inhibition was investigated by comparing the level of activation during the period prior to cued and uncued STOPS in the event-related STOP clusters. The analysis indicated significantly greater activation $(p<$ .01) during the cue period when contrasted to the comparable period prior to uncued STOPS in 10 of 21 regions, including bilateral middle frontal, inferior parietal, and middle temporal regions, as well as left precuneus and lentiform nuclei. None of the midline areas activated during the event-related STOPS (see Table 1 for areas) increased in activation during the cue period when compared to the equivalent uncued pre-no-go period.

\section{DISCUSSION}

From analyzing the patterns of functional brain activity prior to and during the preparation for behavioral control, we found that successful task performance resulted from a pattern of activating task-relevant areas 
Table 3. Areas Activated during the Cue Period Prior to Successful Response Inhibition (STOPS) and Errors of Commission (ERRORS)

\begin{tabular}{|c|c|c|c|c|c|c|c|c|}
\hline \multirow[b]{2}{*}{ Structure } & \multirow[b]{2}{*}{ Brodmann's area } & \multirow[b]{2}{*}{ Hemisphere } & \multirow[b]{2}{*}{ Volume $(\mu l)$} & \multicolumn{3}{|c|}{ Center of Mass } & \multirow[b]{2}{*}{ Sig. } & \multirow[b]{2}{*}{ Cued vs. Uncued } \\
\hline & & & & $x$ & $y$ & $z$ & & \\
\hline \multicolumn{9}{|l|}{ Frontal lobe } \\
\hline \multirow[t]{2}{*}{ Middle frontal gyrus } & 9 & $\mathrm{R}$ & 1635 & 41 & -14 & 27 & & $\Uparrow$ \\
\hline & 6 & $\mathrm{~L}$ & 702 & -28 & 7 & 48 & & $\Uparrow$ \\
\hline \multirow[t]{2}{*}{ Cingulate/medial frontal gyrus } & $24 / 6$ & $\mathrm{R}$ & 339 & 2 & -10 & 46 & & $\Uparrow$ \\
\hline & $32 / 9$ & $\mathrm{~L}$ & 257 & -7 & -53 & 19 & $* * *$ & $\Downarrow$ \\
\hline \multicolumn{9}{|l|}{ Parietal lobe } \\
\hline \multirow[t]{2}{*}{ Superior parietal lobule } & 7 & $\mathrm{~L}$ & 777 & -25 & 64 & 42 & & $\Uparrow$ \\
\hline & 7 & $\mathrm{R}$ & 621 & 29 & 64 & 43 & & $\Uparrow$ \\
\hline Precuneus & 31 & $\mathrm{~L}$ & 251 & -15 & 48 & 33 & & $\Downarrow$ \\
\hline Cingulate gyrus & 23 & $\mathrm{~B}$ & 227 & 1 & 35 & 22 & & $\Uparrow$ \\
\hline Cingulate gyrus/precuneus & $31 / 30$ & $\mathrm{R}$ & 152 & 13 & 56 & 19 & $* * *$ & $\Downarrow$ \\
\hline \multicolumn{9}{|l|}{ Temporal lobe } \\
\hline Middle temporal gyrus & 22 & $\mathrm{R}$ & 266 & 57 & 45 & 3 & & $\Uparrow$ \\
\hline Fusiform & 37 & $\mathrm{~L}$ & 674 & -41 & 60 & -12 & & $\Uparrow$ \\
\hline \multicolumn{9}{|l|}{ Subcortical/insula } \\
\hline Caudate & & $\mathrm{R}$ & 251 & 17 & -4 & 23 & & $\Downarrow$ \\
\hline Insula/claustrum & 13 & $\mathrm{~L}$ & 228 & -36 & 16 & -3 & & $\Downarrow$ \\
\hline Insula & 13 & $\mathrm{~L}$ & 149 & -45 & 15 & 10 & $* * *$ & $\Downarrow$ \\
\hline \multicolumn{9}{|l|}{ Occipital lobe } \\
\hline Inferior occipital gyrus & 18 & $\mathrm{R}$ & 382 & 27 & 84 & -3 & & $\Uparrow$ \\
\hline Middle occipital gyrus & 19 & $\mathrm{~L}$ & 351 & -29 & 82 & 9 & & $\Uparrow$ \\
\hline
\end{tabular}

Positive values for $x, y$, and $z$ coordinates denote locations that are right, posterior, and superior relative to the anterior commissure, respectively. Significance test results (Sig.) indicate cortical areas of decreased activation in the cue period prior to STOPS when compared to the period prior to ERRORS using pairwise $t$ tests. Cued versus uncued indicates the activation in the cue period prior to STOPS in contrast with the comparable period prior to uncued STOPS. (Note: All of these differences were significant at $p<.01$.)

**** $p<.001$.

and deactivating task irrelevant ones. When cues were provided to signify the imminent requirement for cognitive control, activation of the frontal, parietal, and cingulate regions, including bilateral middle frontal, inferior and superior parietal, and dorsal ACC/pre-SMA regions, significantly increased in comparison to the levels detected prior to uncued events. This range of cortical regions is consistent with the attentional network previously demonstrated as necessary for successful inhibitory control (Watanabe et al., 2002; MacDonald et al., 2000; Garavan et al., 1999; Garavan et al., 2002;
Konishi et al., 1998), and is also consistent with the findings of a frontal network of regions being activated in preparation for a demanding cognitive task (Sakai \& Passingham, 2003; Brass \& von Cramon, 2002; Luks et al., 2002).

The present study's findings appear to support the hypothesis that preparation involves activation of taskrelevant cortical areas (Sakai \& Passingham, 2003; Brass \& von Cramon, 2002). Our results, however, represent an extension of this work by providing a comparison between task preparation prior to successes and failures, 


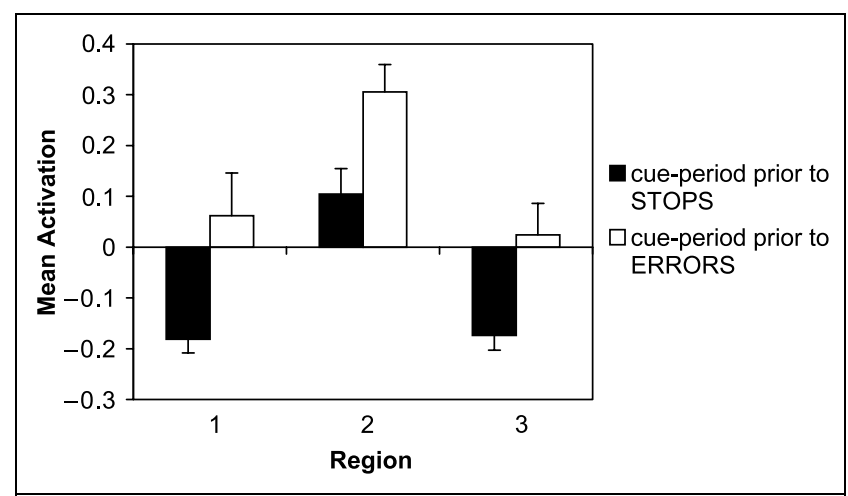

Figure 2. Mean activation for the cue period prior to STOPS and ERRORS for (1) Left cingulate/medial frontal gyrus (BA 32/9), (2) right cingulate gyrus/precuneus (BA 31/30), and (3) left insula (BA 13).

as well as comparing a cued preparation period with a comparable period prior to uncued task performance. The product of these additional comparisons was the finding of a decrease or deactivation in regions not subsequently required for successful behavioral control. These deactivations occurred in concert with the increases in frontoparietal activations, and included areas such as the left medial frontal gyrus, left insula, caudate, and precuneus/posterior cingulate. Two of the areas, the left medial frontal and left insula regions, were also found to be significantly deactivated when comparing the cue period prior to successes with the period prior to failures.

Failure to decrease activation in the left medial frontal and insula regions in concert with the "attentional" increases related directly to failed performance. These two cortical regions have been implicated in neuroimaging studies of emotion (Phan, Wager, Taylor, \& Liberzon, 2002), with the suggestion that cingulate and insula regions are involved in the monitoring of an individual's internal emotional state (Damasio et al., 2000; Simpson et al., 2000; Reiman et al., 1997). A number of studies have also demonstrated these areas to be deactivated during the performance of demanding cognitive tasks that required direction of attention to external cues (Lawrence, Ross, Hoffman, Garavan, \& Stein, 2003; Gray, Braver, \& Raichle, 2002; Gusnard \& Raichle, 2001; Perlstein, Carter, Noll, \& Cohen, 2001; Shulman et al., 1997). Our findings attribute a functional significance to these deactivations as they uniquely predicted whether the subsequent attempt to inhibit would be successful.

A possible hypothesis to account for the observed activation/deactivation during successful task preparation is that cueing may provide an opportunity for topdown control to decrease the resources devoted to monitoring internal states (Gusnard, Akbudak, Shulman, \& Raichle, 2001; Gusnard \& Raichle, 2001; Raichle et al., 2001), while in turn increasing the attentional resources devoted to processing external stimuli. A coordinated process such as this appears to combine the hypothe- sized roles for a number of the cortical regions implicated in the present study. For example, the dorsal ACC/ pre-SMA and dorsolateral PFC regions have been argued to interact in attentional processing through the coordinated response to conflict (Garavan et al., 2002; van Veen \& Carter, 2002; MacDonald et al., 2000). This hypothesis suggests that the ACC plays an evaluative role, detecting conflict between competing behavioral responses. When conflict is detected, the ACC prompts the DLPFC to allocate greater attentional resources to the task. In the present study, the provision of an informative cue was designed to increase the monitoring and top-down control towards the two alternate responses, the prepotent motor response (a button press in response to a go stimulus) and the withhold response (to a no-go stimulus). The activation results indicated that in the period following a cue, both the dorsal ACC/ pre-SMA and DLPFC regions had significantly greater activation than baseline levels, and significantly greater levels than the comparable period prior to uncued events.

The increase in dorsal ACC and DLPFC activation might also account for the deactivations in the taskirrelevant midline areas (left medial frontal gyrus, left insula and right posterior cingulate). Several studies have found a reciprocal suppression of emotion/cognition interactions, where performance of cognitively demanding tasks results in the suppression of cortical regions important to emotion, such as the rostral ACC, orbitofrontal cortex, amygdala, and insular cortex (Perlstein et al., 2001; Bush, Luu, \& Posner, 2000; Mayberg et al., 1999; Drevets \& Raichle, 1998). Our findings are consistent with this hypothesis and, furthermore, suggest that top-down control also has the capacity to deactivate emotion-related cortical regions in the preparation for, as well as during, a cognitively demanding task.

\section{Implications}

The present study therefore offers an insight into how the brain prepares for successful behavioral control. The concurrent activation/deactivation pattern observed suggests that although increased activation in task-appropriate areas is beneficial to competent task performance, nonsuppression of task-irrelevant activation may lead to interference with task performance. This finding may have application to those groups that have difficulty with behavioral control. Failures of this type may not necessarily reflect inactivation or impairment of task-appropriate areas, but rather the inability to deactivate or maintain the deactivation of task-inappropriate areas, or perhaps a deficit in the coordination of attentional allocation. For example, Lawrence et al. (2003) have demonstrated that subjects performing the same attentionally demanding task can have different patterns of functional activations and deactivations. Their results showed that participants had either activated attentional regions, or deactivated "emotional processing" areas, or 
engaged in both processes, but all patterns had led to successful performance.

An application of this hypothesis can be made in the case of patients with traumatic brain injury for whom a common outcome is severe difficulty with tasks requiring sustained attention (Bate, Mathias, \& Crawford, 2001b; Chan, 2001; Robertson, Manly, Andrade, Baddeley, \& Yiend, 1997; Whyte, Polansky, Fleming, Coslett, \& Cavallucci, 1995). However, exogenous cueing of attention typically results in improvements to performance, which indicate patients are within "normal" limits (Bate, Mathias, \& Crawford, 2001a; Whyte, Fleming, Polansky, Cavallucci, \& Coslett, 1997). This pattern of performance suggests that while the underlying attentional system is intact, the ability to maintain appropriate distribution of attentional resources may be impaired. In these individuals and others with impaired behavioral control, the allocation of resources may be overly distributed to monitoring of internal states, which during sustained attention tasks leads to interference with performance. However, when an individual is provided with exogenous cueing, it prompts the redistribution of attentional resources.

This hypothesis would suggest that poor performance in patient groups might result from impairment to the functional interaction between areas that detect heightened task demands (e.g., midline areas that monitor response conflict) and DLPFC areas. Although the literature indicates dysfunction in these cortical areas is a common sequelae of TBI (Yount et al., 2002; Bush et al., 1999; Fontaine, Azouvi, Remy, Bussel, \& Samson, 1999; Gross, Kling, Henry, Herndon, \& Lavretsky, 1996; Matochik, Zametkin, Cohen, Hauser, \& Weintraub, 1996), direct confirmation of this hypothesis has yet to be undertaken, although functional imaging of behavioral control tasks such as the go/no-go in individuals with compromised attentional function may prove illuminating.

\section{Effects of Cueing on ERRORS}

An unexpected finding, but one that deserves further investigation, was the effect of providing cues to the cortical activation seen during a failed attempt to exert behavioral control. A comparison of cued and uncued ERRORS indicated greater activation for cued ERRORS in a number of regions, most notably left sided inferior frontal (BA 44 and 47), insula (BA 13), and transverse temporal (BA 42) regions. One explanation for this result is that cued ERRORS might provoke a greater self-admonishment from participants, as they had been unable to exert behavioral control despite the warning of its imminent requirement. Consistent with this hypothesis, previous functional imaging studies of emotional and verbal/subvocalization processing (Phan et al., 2002; Fiez, 2001; Cabeza \& Nyberg, 2000) have demonstrated activation in these same regions.

\section{Conclusions}

The results of the present study offer an insight into the cortical areas that are the precursors to inhibitory failure and success. They demonstrate that task preparation includes the top-down control of mobilizing the necessary resources to complete a task prior to the task activity itself being undertaken, which includes both the activation of task-relevant cortical regions and the deactivation of task-irrelevant regions. Furthermore, this interrelationship between cortical activation changes directly influences behavioral performance.

\section{METHODS}

\section{Subjects and Task Design}

Fifteen right-handed subjects (10 women, mean age 30 , range 23-40), reporting no history of neurological or psychological impairment, completed a go/no-go task, visually presented in Figure 3 based on our earlier work (Garavan et al., 2002), after providing written informed consent. The letters $\mathrm{X}$ and $\mathrm{Y}$ were presented serially in an alternating pattern at $1 \mathrm{~Hz}$ (900-msec stimuli on screen, 100 msec blank) and subjects were required to make a button press response to each letter. Responses and response speed were recorded. Responses were to be withheld to lure stimuli: A lure occurred when the alternation was interrupted (e.g., the fifth stimulus in the train $\mathrm{X}-\mathrm{Y}-\mathrm{X}-\mathrm{Y}-\mathrm{Y}-\mathrm{X}-\mathrm{Y}$ ). The go/no-go task employed a mixed block and event-related fMRI design to identify the functional areas activated during both no-go decision events, and the block of trials following a visual cue that was introduced 2 to 7 secs prior to the no-go event (cue period). The font of an $\mathrm{X}$ or $\mathrm{Y}$ was changed to strikethrough (e.g., X) for the visual cue stimuli. The event-related design of this experiment allowed the lures to be distributed unpredictably throughout the stimuli stream. During fMRI scanning, subjects completed four runs that contained 1176 targets (go stimuli) and 80 lures (no-go stimuli) that included an equal distribution of cued and uncued lures. This ratio resulted in an average interlure interval of $15.75 \mathrm{sec}$.

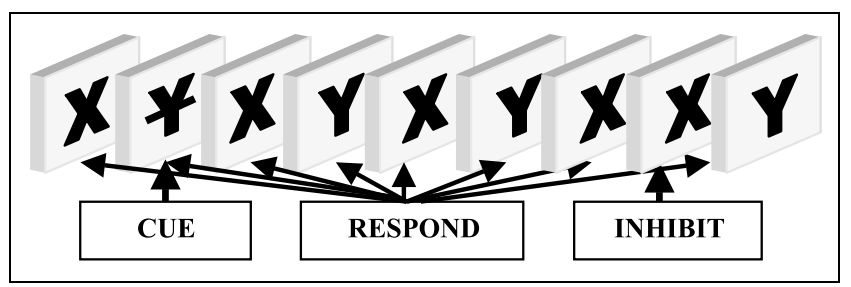

Figure 3. The $\mathrm{XY}$ go/no-go task employed for the current study. Subjects were required to make a button press response to each letter (respond), which were presented at $1 \mathrm{~Hz}$ (900 msec on screen, 100 -msec interstimulus interval). Responses were to be withheld to no-go events (indicated by inhibit), which on $50 \%$ of occasions was preceded by a visual cue (cue) occurring two to seven trials in advance of the no-go event. 


\section{Scanning Parameters and Data Analyses}

All scanning was conducted on a $1.5 \mathrm{~T}$ Siemens VISION scanner in which foam padding was used to restrict head movements. Contiguous 5-mm sagittal slices covering the entire brain were collected using single-shot, T2* weighted echo-planar imaging sequence $(\mathrm{TE}=50 \mathrm{msec}$; $\mathrm{TR}=2000 \mathrm{msec} ; \mathrm{FOV}=256 \mathrm{~mm} ; 64 \times 64-\mathrm{mm}$ matrix size in-plane resolution). High-resolution T1-weighted structural MPRAGE images (FOV $=256 \mathrm{~mm}$, isotropic $1-\mathrm{mm}$ voxels) were acquired following functional imaging to allow subsequent activation localization and spatial normalization. Stimuli were delivered using an IFIS-SA stimulus-delivery system (MRI Devices, Waukesha, WI), which was equipped with a head-coil-mounted $640 \times 480$ LCD panel. This shielded LCD screen is mounted on the head coil, directly in the subjects' line of vision.

All analyses were conducted using AFNI software (Cox, 1996). Following image reconstruction, the time series data were time shifted using Fourier interpolation to remove differences in slice acquisition times, and motion corrected using 3-D volume registration (least squares alignment of three translational and three rotational parameters). Activation outside the brain was also removed using edge detection. No subjects showed significant residual motion, thus allowing for all 15 to be included. The first five and last two images of each run were excluded from further analyses, as these images were acquired during brief rest periods.

Separate hemodynamic response functions at 2-sec temporal resolution were calculated using deconvolution techniques for successful response inhibition (STOPS) and errors of commission (ERRORS) in both the cued and uncued conditions. Block activation functions for the cue periods were identified as the period beginning with the presentation of the cue stimulus and ending with the trial immediately prior to the presentation of a lure. Although the stimulus stream was presented at $1 \mathrm{~Hz}$, all events of interest were timelocked to the beginning of the 2-sec whole-brain volume acquisition.

A mixed regression analysis was used whereby cue period blocks were calculated as a percentage change relative to baseline. The baseline in this design is an implicit one and is indicative of ongoing and remaining task-related processing after the variance related to the other types of events have been removed. Separate impulse response functions (IRFs) were calculated for the four event-related conditions: Cued STOPS, cued ERRORS, uncued STOPS, and uncued ERRORS. A nonlinear regression program determined the best fitting gamma-variate function for these IRFs (Cohen, 1997) as previously described (Garavan et al., 1999). The area under the curve of the gamma-variate function was expressed as a percentage of the area under the baseline. The percentage area (event-related activation) and percentage change map (block activation) voxels were resampled at $1-\mathrm{mm}^{3}$ resolution, then warped into standard Talairach space (Talairach \& Tournoux, 1988) and spatially blurred with a 3-mm isotropic rms Gaussian kernel.

Group activation maps for each condition (cued and uncued STOPS, cued and uncued ERRORS, cue period prior to STOPS and ERRORS) were determined with one-sample $t$ tests against the null hypothesis of zero event-related activation changes (i.e., no change relative to tonic task-related activity). Significant voxels passed a voxelwise statistical threshold $(t=4.14, p=.001)$ and were required to be part of a larger $142-A$ l cluster of contiguous significant voxels. Thresholding was determined through Monte Carlo simulations and resulted in a $5 \%$ probability of a cluster surviving due to chance.

The activation maps were then combined within categories, deriving OR maps of cued and uncued STOPS, cued and uncued ERRORS, and cue periods prior to STOPS and ERRORS. An OR map includes the voxels of activation indicated as significant from either of the constituent maps. The mean activation for clusters in the combined maps was calculated for the purposes of an ROI analysis, and these data were used for a series of pairwise comparisons between conditions, corrected using a modified Bonferroni procedure for multiple comparisons (Keppel, 1991).

\section{Secondary Analysis}

To ensure that activation produced during the cue period did not overlap with activation produced by the events, an additional analysis that accommodated the hemodynamic lag of the cue period was performed. Blocks corresponding to the cue periods were convolved with a standard hemodynamic response and all analyses were repeated. This analysis produced identical results to the initial analysis so only the former will be reported.

Following initial analysis it was decided to examine the period of activation prior to uncued lures. To provide an equivalent period for comparison, the length and location of cue periods prior to cued lures were transposed to the periods prior to uncued lures. Due to the temporal spacing of lures, the creation of blocks prior to uncued lures did not overlap with other events of interest. The activation maps for blocks prior to uncued STOPS and uncued ERRORS were then calculated using the method described above.

Due to the small number of cued ERRORS available for the ERROR analysis, we examined the effect of collapsing cued and uncued ERROR events into a single condition. All group analyses were repeated and yielded identical results for the cue period blocks, and cued and uncued STOPS. The new activation map for combined ERRORS contained six clusters, all of which overlapped with clusters identified in the OR ERROR map of 
the initial analyses. An ROI analysis was performed to compare the level of activation for cued and uncued ERRORS in these six clusters, revealing significantly greater activation in the right inferior parietal region (BA 40) during the cued ERROR condition. Due to the similarity between the OR ERROR map and the combined ERROR map, the results of the initial analysis that allowed for comparison of cued and uncued ERROR activations was reported.

\section{Acknowledgments}

This research was supported by USPHS grant DA14100 and GCRC M01 RR00058, and NIMH grants MH63434 and MH65350. The assistance of Patrick O'Donnell, Catherine Fassbender, Andrea Kübler, and Ian Robertson are gratefully acknowledged.

Reprint request should be sent to Hugh Garavan, PhD, Department of Psychology, Trinity College Dublin, Dublin 2, Ireland, or via e-mail: Hugh.Garavan@tcd.ie.

The data reported in this experiment have been deposited in the fMRI Data Center (http://www.fmridc.org). The accession number is $2-2003-114 \mathrm{GH}$.

\section{REFERENCES}

Barkley, R. A. (1997). Behavioral inhibition, sustained attention, and executive functions: Constructing a unifying theory of ADHD. Psychological Bulletin, 121, 65-94.

Bate, A. J., Mathias, J. L., \& Crawford, J. R. (2001a). The covert orienting of visual attention following severe traumatic brain injury. Journal of Clinical and Experimental Neuropsychology, 23, 386-398.

Bate, A. J., Mathias, J. L., \& Crawford, J. R. (2001b). Performance on the Test of Everyday Attention and standard tests of attention following severe traumatic brain injury. Clinical Neuropsychologist, 15, 405-422.

Brass, M., \& von Cramon, D. Y. (2002). The role of the frontal cortex in task preparation. Cerebral Cortex, 12, 908-914.

Bush, G., Frazier, J. A., Rauch, S. L., Seidman, L. J., Whalen, P. J., Jenike, M. A., Rosen, B. R., \& Biederman, J. (1999). Anterior cingulate cortex dysfunction in attention-deficit/ hyperactivity disorder revealed by fMRI and the counting Stroop. Biological Psychiatry, 45, 1542-1552.

Bush, G., Luu, P., \& Posner, M. I. (2000). Cognitive and emotional influences in anterior cingulate cortex. Trends in Cognitive Sciences, 4, 215-222.

Cabeza, R., \& Nyberg, L. (2000). Imaging cognition II: An empirical review of 275 PET and fMRI studies. Journal of Cognitive Neuroscience, 12, 1-47.

Chan, R. C. (2001). A further study on the sustained attention response to task (SART): The effect of age, gender and education. Brain Injury, 15, 819-829.

Cohen, M. S. (1997). Parametric analysis of fMRI data using linear systems methods. Neuroimage, 6, 93-103.

Cox, R. W. (1996). AFNI: Software for analysis and visualization of functional magnetic resonance neuroimages. Computer and Biomedical Research, 29, 162-173.

Cummings, J. L., \& McPherson, S. (2001). Neuropsychiatric assessment of Alzheimer's disease and related dementias. Aging (Milano), 13, 240-246.

Damasio, A. R., Grabowski, T. J., Bechara, A., Damasio, H., Ponto, L. L., Parvizi, J., \& Hichwa, R. D. (2000).
Subcortical and cortical brain activity during the feeling of self-generated emotions. Nature Neuroscience, 3, 1049-1056.

Drevets, W., \& Raichle, M. (1998). Reciprocal suppression of regional cerebral blood flow during emotional versus higher cognitive processes: Implications for interactions between emotion and cognition. Cognition Emotion, 12, 353-385.

Fiez, J. A. (2001). Bridging the gap between neuroimaging and neuropsychology: Using working memory as a case-study. Journal of Clinical and Experimental Neuropsychology, 23, 19-31.

Fontaine, A., Azouvi, P., Remy, P., Bussel, B., \& Samson, Y. (1999). Functional anatomy of neuropsychological deficits after severe traumatic brain injury. Neurology, 53, 1963-1968.

Garavan, H., Ross, T. J., Murphy, K., Roche, R. A., \& Stein, E. A. (2002). Dissociable executive functions in the dynamic control of behavior: Inhibition, error detection, and correction. Neuroimage, 17, 1820-1829.

Garavan, H., Ross, T. J., \& Stein, E. A. (1999). Right hemispheric dominance of inhibitory control: An event-related functional MRI study. Proceedings of the National Academy of Sciences, U.S.A., 96, 8301-8306.

Gray, J. R., Braver, T. S., \& Raichle, M. E. (2002). Integration of emotion and cognition in the lateral prefrontal cortex. Proceedings of the National Academy of Sciences, U.S.A., 99, 4115-4120.

Gross, H., Kling, A., Henry, G., Herndon, C., \& Lavretsky, H. (1996). Local cerebral glucose metabolism in patients with long-term behavioral and cognitive deficits following mild traumatic brain injury. Journal of Neuropsychiatry and Clinical Neurosciences, 8, 324-334.

Gusnard, D. A., Akbudak, E., Shulman, G. L., \& Raichle, M. E. (2001). Medial prefrontal cortex and self-referential mental activity: Relation to a default mode of brain function. Proceedings of the National Academy of Sciences, U.S.A., 98, 4259-4264.

Gusnard, D. A., \& Raichle, M. E. (2001). Searching for a baseline: Functional imaging and the resting human brain. Nature Reviews Neuroscience, 2, 685-694.

Keppel, G. (1991). Design and analysis: A researcher's handbook. Englewood Cliffs, NJ: Prentice Hall.

Konishi, S., Nakajima, K., Uchida, I., Sekihara, K., \& Miyashita, Y. (1998). No-go dominant brain activity in human inferior prefrontal cortex revealed by functional magnetic resonance imaging. European Journal of Neuroscience, 10, 1209-1213.

Konrad, K., Gauggel, S., Manz, A., \& Scholl, M. (2000). Inhibitory control in children with traumatic brain injury (TBI) and children with attention deficit/hyperactivity disorder (ADHD). Brain Injury, 14, 859-875.

Lawrence, N., Ross, T. J., Hoffman, R., Garavan, H., \& Stein, E. A. (2003). Networks of sustained attention; activation and deactivation determine individual ability, Journal of Cognitive Neuroscience, 15, 1028-1038.

Liddle, P. F., Kiehl, K. A., \& Smith, A. M. (2001). Event-related fMRI study of response inhibition. Human Brain Mapping, 12, 100-109.

Luks, T. L., Simpson, G. V., Feiwell, R. J., \& Miller, W. L. (2002). Evidence for anterior cingulate cortex involvement in monitoring preparatory attentional set. Neuroimage, 17, 792-802.

MacDonald, A. W., III, Cohen, J. D., Stenger, V. A., \& Carter, C. S. (2000). Dissociating the role of the dorsolateral prefrontal and anterior cingulate cortex in cognitive control. Science, 288, 1835-1838. 
Matochik, J. A., Zametkin, A. J., Cohen, R. M., Hauser, P., \& Weintraub, B. D. (1996). Abnormalities in sustained attention and anterior cingulate metabolism in subjects with resistance to thyroid hormone. Brain Research, 723, 23-28.

Mayberg, H. S., Liotti, M., Brannan, S. K., McGinnis, S., Mahurin, R. K., Jerabek, P. A., Silva, J. A., Tekell, J. L., Martin, C. C., Lancaster, J. L., \& Fox, P. T. (1999). Reciprocal limbic-cortical function and negative mood: Converging PET findings in depression and normal sadness. American Journal of Psychiatry, 156, 675-682.

Perlstein, W. M., Carter, C. S., Noll, D. C., \& Cohen, J. D. (2001). Relation of prefrontal cortex dysfunction to working memory and symptoms in schizophrenia. American Journal of Psychiatry, 158, 1105-1113.

Phan, K. L., Wager, T., Taylor, S. F., \& Liberzon, I. (2002). Functional neuroanatomy of emotion: A meta-analysis of emotion activation studies in PET and fMRI. Neuroimage, 16, 331-348.

Raichle, M. E., MacLeod, A. M., Snyder, A. Z., Powers, W. J., Gusnard, D. A., \& Shulman, G. L. (2001). A default mode of brain function. Proceedings of the National Academy of Sciences, U.S.A., 98, 676-682.

Rapport, L. J., Van Voorhis, A., Tzelepis, A., \& Friedman, S. R. (2001). Executive functioning in adult attention-deficit hyperactivity disorder. Clinical Neuropsychologist, 15, 479-491.

Reiman, E. M., Lane, R. D., Ahern, G. L., Schwartz, G. E., Davidson, R. J., Friston, K. J., Yun, L. S., \& Chen, K. (1997). Neuroanatomical correlates of externally and internally generated human emotion. American Journal of Psychiatry, 154, 918-925.

Robertson, I. H., Manly, T., Andrade, J., Baddeley, B. T., \& Yiend, J. (1997). "Oops!": Performance correlates of everyday attentional failures in traumatic brain injured and normal subjects. Neuropsychologia, 35, 747-758.

Rogers, R. D., \& Monsell, S. (1995). Costs of a predictable switch between simple cognitive tasks. Journal of Experimental Psychology: General, 124, 207-231.

Sakai, K., \& Passingham, R. E. (2003). Prefrontal interactions reflect future task operations. Nature Neuroscience, 6 , 75-81.

Shulman, G. L., Fiez, J. A., Corbetta, M., Buckner, R. L., Miezin, F. M., Raichle, M. E., \& Petersen, S. E. (1997). Common blood flow changes across visual tasks: II. Decreases in cerebral cortex. Journal of Cognitive Neuroscience, 9, 648-663.

Simpson, J. R., Ongur, D., Akbudak, E., Conturo, T. E., Ollinger, J. M., Snyder, A. Z., Gusnard, D. A., \& Raichle, M. E. (2000).

The emotional modulation of cognitive processing: An fMRI study. Journal of Cognitive Neuroscience, 12, 157-170.

Stevens, J., Quittner, A. L., Zuckerman, J. B., \& Moore, S. (2002). Behavioral inhibition, self-regulation of motivation, and working memory in children with attention deficit hyperactivity disorder. Developmental Neuropsychology, 21, 117-139.

Talairach, J., \& Tournoux, P. (1988). Co-planar stereotaxic atlas of the buman brain. New York: Thieme.

Tekin, S., \& Cummings, J. L. (2002). Frontal-subcortical neuronal circuits and clinical neuropsychiatry: An update. Journal of Psychosomatic Research, 53, 647-654.

van Veen, V., \& Carter, C. S. (2002). The anterior cingulate as a conflict monitor: fMRI and ERP studies. Physiology and Behavior, 77, 477-482.

van Veen, V., Cohen, J. D., Botvinick, M. M., Stenger, V. A., \& Carter, C. S. (2001). Anterior cingulate cortex, conflict monitoring, and levels of processing. Neuroimage, 14, 1302-1308.

Watanabe, J., Sugiura, M., Sato, K., Sato, Y., Maeda, Y., Matsue, Y., Fukuda, H., \& Kawashima, R. (2002). The human prefrontal and parietal association cortices are involved in NO-GO performances: An event-related fMRI study. Neuroimage, 17, 1207-1216.

Whyte, J., Fleming, M., Polansky, M., Cavallucci, C., \& Coslett, H. B. (1997). Phasic arousal in response to auditory warnings after traumatic brain injury. Neuropsychologia, 35, 313-324.

Whyte, J., Polansky, M., Fleming, M., Coslett, H. B., \& Cavallucci, C. (1995). Sustained arousal and attention after traumatic brain injury. Neuropsychologia, 33, 797-813.

Yount, R., Raschke, K. A., Biru, M., Tate, D. F., Miller, M. J., Abildskov, T., Gandhi, P., Ryser, D., Hopkins, R. O., \& Bigler, E. D. (2002). Traumatic brain injury and atrophy of the cingulate gyrus. Journal of Neuropsychiatry and Clinical Neurosciences, 14, 416-423. 